TITLE:

\title{
The concise synthesis of chiral tfb ligands and their application to the rhodium-catalyzed asymmetric arylation of aldehydes
}

\section{$\operatorname{AUTHOR}(S)$ :}

Nishimura, Takahiro; Kumamoto, Hana; Nagaosa, Makoto; Hayashi, Tamio

\section{CITATION:}

Nishimura, Takahiro ... [et al]. The concise synthesis of chiral tfb ligands and their application to the rhodium-catalyzed asymmetric arylation of aldehydes. Chemical Communications 2009, 38: 5713-5715

\section{ISSUE DATE:}

2009

URL:

http://hdl.handle.net/2433/87060

\section{RIGHT:}

c 2009 The Royal Society of Chemistry. 許諾条件により本文は2010-1101に公開.; この論文は出版社版でありません。引用の際には出版社版 をご確認ご利用ください。; This is not the published version. Please cite only the published version. 


\title{
The concise synthesis of chiral tfb ligands and their application to rhodium-catalyzed asymmetric arylation of aldehydes
}

\author{
Takahiro Nishimura,* Hana Kumamoto, Makoto Nagaosa, and Tamio Hayashi*
}

$C_{2}$-Symmetric tetrafluorobenzobarrelene ligands were prepared through the transition metal-catalyzed cross-coupling of an enantiopure tetrafluorobenzobicyclo[2.2.2]octatriene-2,5-diyl bis(trifluoro-methanesulfonate) with organometallic reagents. The diene ligands realized the rhodium-catalyzed asymmetric addition of arylboronic acids to aromatic aldehydes.

Chiral dienes have been recently developed as a new class of chiral ligands for the transition metals, realizing highly efficient and enantioselective reactions. ${ }^{1}$ Of the diene ligands bearing diverse bicyclic skeletons, tetrafluorobenzobicyclo[2.2.2] octatriene (tetrafluorobenzobarrelene; tfb) $\mathbf{1 a}$ and its derivatives $^{2}$ are attractive compounds because of their high coordination ability toward transition metals due to the small bite angle and electron-deficient characters. ${ }^{3}$ In addition, the synthesis of the $\mathrm{tfb}$ dienes is easy; i.e. tfb 1a is prepared in one step by the formal [ $4+2]$ cycloaddition of benzene with tetrafluorobenzyne generated from pentafluorophenyllithium or -magnesium (Scheme 1, route a). ${ }^{2}$ The use of 1,4disubstituted benzenes provides chiral tfb dienes. Recently, we reported the synthesis of enantiomerically pure disubstituted tfb dienes (1b and 1c) via cycloaddition of tetrafluorobenzyne with the 1,4-disubstituted benzenes and their application to the rhodium- and iridium-catalyzed asymmetric addition of arylboronic acids. ${ }^{4}$ One drawback of the direct preparation of chiral tfb dienes is the difficulty of the synthesis of tfb $\mathbf{1}$ substituted with aromatic groups. Provided that the enantiopure ditriflate $\mathbf{2}$ is obtained, it is possible to prepare diverse chiral tfb dienes by transition metal-catalyzed cross-coupling reactions (route b). Here we report the development of $C_{2}$-symmetric disubstituted tetrafluorobenzobicyclo[2.2.2] octatrienes $\mathbf{1}$ and their successful application to the rhodium-catalyzed asymmetric arylation of aldehydes with arylboronic acids.

Chiral ditriflate $\mathbf{2}$ and tfb ligands 1d-f were prepared through the straightforward pathways (Scheme 2). The $[4+$

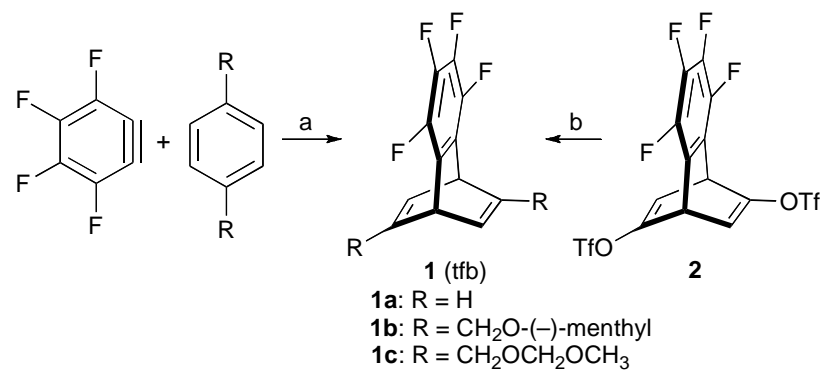

Scheme 1 Tetrafluorobenzobarrelenes (tfb).

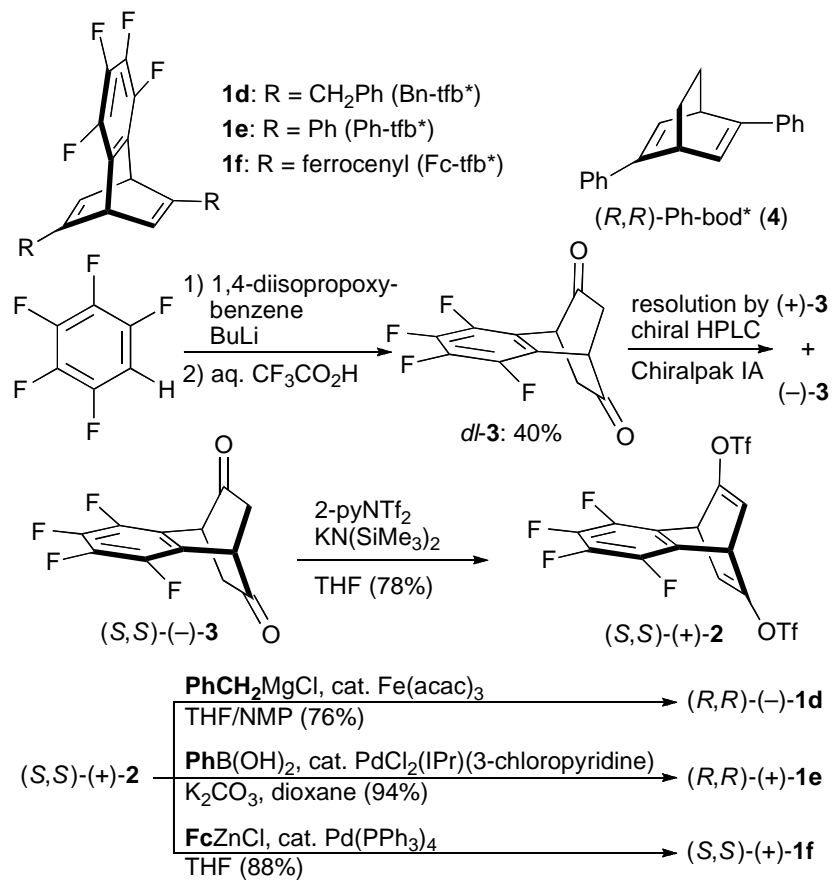

Scheme 2 Synthesis of $C_{2}$-symmetric tetrafluorobenzobarrelenes ( $\mathrm{tfb}^{*}$ ).

2] cycloaddition of 1,4-diisopropoxybenzene with tetrafluorobenzyne followed by hydrolysis gave $d l-3$ in $40 \%$ yield. ${ }^{5}$ The resolution of diketone $d l-3$ by use of a chiral stationary phase column (Chiralpak IA) ${ }^{6}$ gave both enantiomers $(+)-3$ and $(-)-3$, which were transformed into ditriflate 2. ${ }^{7}$ Enantiopure ditriflate 2 was subjected to the cross-coupling reactions with benzylmagnesium chloride, ${ }^{8}$ phenylboronic acid, ${ }^{9}$ and ferrocenylzinc chloride ${ }^{10}$ leading to 1d, 1e, and 1f, respectively, in good yields. The reaction of chiral dienes 1 d-f with $\left[\mathrm{RhCl}\left(\mathrm{C}_{2} \mathrm{H}_{4}\right)_{2}\right]_{2}$ gave rhodium complexes $[\mathrm{RhCl}(\mathbf{1})]_{2}$ in high yields (Scheme 3 ). The absolute configuration of $(S, S)$-1f was assigned by the X-ray crystallographic analysis of its rhodium complex $\operatorname{Rh}(\mathbf{1 f})\left[\left(\eta^{6}-\right.\right.$ $\left.\mathrm{C}_{6} \mathrm{H}_{5}\right) \mathrm{BPh}_{3}$ ] (Scheme 3, Figure 1). ${ }^{11}$

Asymmetric synthesis of diarylmethanols by the enantioselective arylation of aldehydes remains to be a very important objective in organic synthesis. ${ }^{12}$ A successful development has been achieved in the asymmetric addition of arylzinc reagents to aldehydes by use of chiral ligands. ${ }^{13}$ The transition metal-catalyzed asymmetric addition of organometallic reagents to aldehydes is another useful method for the synthesis of chiral diarylmethanols, where arylboronic acids are used as attractive arylating reagents. Since the first 


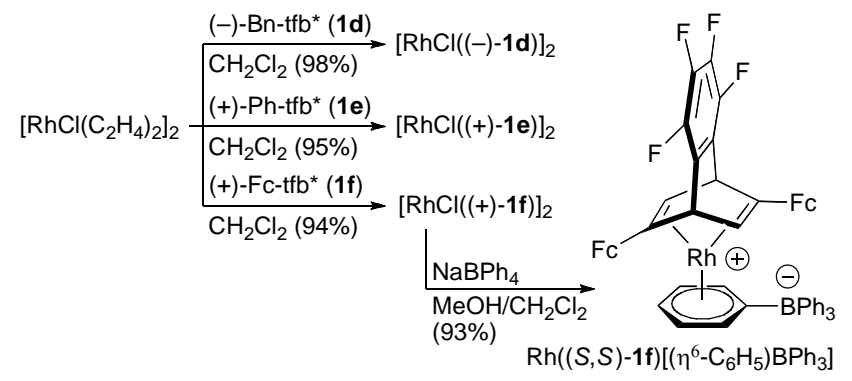

Scheme 3 Synthesis of rhodium complexes.

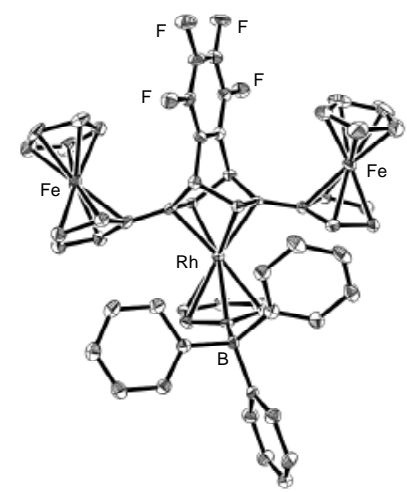

Fig. 1 ORTEP illustration of $\mathrm{Rh}((S, S)-\mathbf{1 f})\left[\left(\eta^{6}-\mathrm{C}_{6} \mathrm{H}_{5}\right) \mathrm{BPh}_{3}\right]$ with thermal ellipsoids drawn at $50 \%$ probability level. The solvent molecule $\left(\mathrm{CH}_{2} \mathrm{Cl}_{2}\right)$ and hydrogens are omitted for clarity.

report of the rhodium-catalyzed asymmetric arylation of aldehydes by Miyaura in $1998,{ }^{14 \mathrm{a}} \mathrm{Rh},{ }^{1 \mathrm{k},}{ }^{14} \mathrm{Ni},{ }^{15}$ and $\mathrm{Ru}-$ catalyzed ${ }^{16}$ reactions have been developed.

The new rhodium complexes having tfb ligands 1d-1f were tested for the asymmetric arylation of aldehydes with arylboronic acids. The ligands $\mathbf{1 b}, \mathbf{1 c}$, and Ph-bod (4) $)^{1 \mathrm{c}, \mathrm{d}}$ were also used for comparison. Treatment of 1-naphthaldehyde (5a) with phenylboronic acid $\mathbf{( 6 m )}$ in the presence of $[\mathrm{RhCl}(\mathbf{1 b})]_{2}$ (3 mol\% of $\left.\mathrm{Rh}\right)$ and $\mathrm{KOH}$ (1.5 equiv) in dioxane $/ \mathrm{H}_{2} \mathrm{O}(4 / 1)$ at $30{ }^{\circ} \mathrm{C}$ for $12 \mathrm{~h}$ gave diarylmethanol 7am in low yield and ee (25\%, 16\% ee) (Table 1, entry 1$)$. The yields of 7 am were also low in the reaction by use of the tfb ligands (1c and 1d) substituted with alkyl groups (entries 2 and 3). On the other hand, Ph-tfb*(1e) displayed higher catalytic activity and enantioselectivity giving 7am in $94 \%$ yield with $49 \%$ ee (entry 4). The same yield and enantioselectivity were observed in the reaction by use of $\mathrm{Ph}$ bod* (4), which has phenyl groups on a bicyclo[2.2.2] octadiene skeleton (entry 5). These results imply that the electron-deficient character of the diene part substituted with the phenyl group improves the catalytic activity. Higher enantioselectivity was obtained with tfb ligand 1f (Fc-tfb*) substituted with ferrocenyl groups, where the ee of $7 \mathbf{a m}$ was $72 \%$ (entry 6 ). The reaction solvents had a significant influence on the enantioselectivity. Thus, the reaction in protic solvents improved the ee of 7am (entries 79 ), and the highest enantioselectivity ( $86 \%$ ee) was observed in tert-butyl alcohol (entry 9). The reaction with the catalyst loading of $1 \mathrm{~mol} \%$ of rhodium proved to be completed within $3 \mathrm{~h}$ (entry 10). The absolute configuration of 7 am produced by use of $(S, S)$-1f was determined to be $(S)$ by comparison of its specific rotation and the retention time of the chiral HPLC
Table 1 Asymmetric addition of phenylboronic acid $(6 \mathrm{~m})$ to 1naphthaldehyde (5a) ${ }^{a}$

\begin{tabular}{|c|c|c|c|c|c|}
\hline \multicolumn{2}{|c|}{$5 a$} & $\begin{array}{c}\mathrm{PhB}(\mathrm{OH})_{2} \\
\text { (2 equiv) } \\
6 \mathrm{~m}\end{array}$ & $\begin{array}{l}{[\mathrm{RhCl}(\text { diene })]_{2}} \\
(3 \mathrm{~mol} \% \mathrm{Rh}) \\
\mathrm{KOH}(1.5 \text { equiv) } \\
\text { solvent } \\
30^{\circ} \mathrm{C}, 12 \mathrm{~h}\end{array}$ & 7 an & ${ }_{l}^{\mathrm{OH}}$ \\
\hline Entry & Ligand & Solvent & & Yield $(\%)^{b}$ & Ee $(\%)^{c}$ \\
\hline 1 & $1 b$ & 1,4-dioxan & $\mathrm{e} / \mathrm{H}_{2} \mathrm{O}(4 / 1)$ & $25^{d}$ & $16(S)$ \\
\hline 2 & $1 c$ & 1,4-dioxan & $\mathrm{e} / \mathrm{H}_{2} \mathrm{O}(4 / 1)$ & $30^{d}$ & $43(S)$ \\
\hline 3 & 1d & 1,4-dioxane & $\mathrm{e} / \mathrm{H}_{2} \mathrm{O}(4 / 1)$ & $49^{d}$ & $27(S)$ \\
\hline 4 & $1 e$ & 1,4-dioxane & $\mathrm{e} / \mathrm{H}_{2} \mathrm{O}(4 / 1)$ & 94 & $49(S)$ \\
\hline 5 & 4 & 1,4-dioxan & $\mathrm{e} / \mathrm{H}_{2} \mathrm{O}(4 / 1)$ & 94 & $49(S)$ \\
\hline 6 & 1f & 1,4-dioxan & $\mathrm{e} / \mathrm{H}_{2} \mathrm{O}(4 / 1)$ & 94 & $72(S)$ \\
\hline 7 & 1f & methanol & & 99 & $78(S)$ \\
\hline 8 & 1f & 2-propanol & & 99 & $84(S)$ \\
\hline 9 & 1f & tert-butyl a & lcohol & 94 & $86(S)$ \\
\hline $10^{e}$ & 1f & tert-butyl a & lcohol & 95 & $86(S)$ \\
\hline
\end{tabular}

${ }^{a}$ Reaction conditions; [RhCl(diene) $]_{2}(3.75 \mu \mathrm{mol}, 3 \mathrm{~mol} \%$ of $\mathrm{Rh}), 5 \mathrm{a}$ (0.25 mmol), $6 \mathrm{~m}(0.50 \mathrm{mmol}), \mathrm{KOH}(0.38 \mathrm{mmol})$, solvent $(1.0 \mathrm{~mL})$, at $30{ }^{\circ} \mathrm{C}$ for $12 \mathrm{~h} .{ }^{b}$ Isolated yield. ${ }^{c}$ Determined by HPLC analysis with chiral stationary phase column: Chiralcel OD-H. ${ }^{d}$ Unreacted 5a was observed. ${ }^{e}$ Performed with $[\operatorname{RhCl}((S, S)-\mathbf{1 f})]_{2}(1 \mathrm{~mol} \%$ of Rh) for $3 \mathrm{~h}$.

Table 2 Asymmetric addition of arylboronic acids (6) to aromatic aldehydes $\mathbf{5}^{a}$

\begin{tabular}{|c|c|c|c|c|}
\hline $\begin{array}{c}\mathrm{Ar}^{1} \mathrm{CHO}+ \\
\mathbf{5} \mathbf{a}-\mathbf{k}\end{array}$ & $\begin{array}{c}\mathrm{Ar}^{2} \mathrm{~B}(\mathrm{OH})_{2} \\
6 \mathbf{m}-\mathbf{u}\end{array}$ & $\begin{array}{l}{\left[\mathrm{RhCl}\left((\mathrm{S}, \mathrm{S})-\mathrm{Fc}-\mathrm{tfb}{ }^{\star}(\mathbf{1 f})\right)\right]} \\
(1 \text { or } 3 \mathrm{~mol} \% \mathrm{Rh}) \\
\mathrm{KOH}(1.5 \text { equiv), } t \text {-BuO } \\
30^{\circ} \mathrm{C}, 3 \text { or } 12 \mathrm{~h}\end{array}$ & $\overrightarrow{\mathrm{H}}$ & \\
\hline Entry & $\mathrm{Ar}^{1}$ & $\mathrm{Ar}^{2}$ & Yield $^{b}$ & $\mathrm{Ee}^{c}$ \\
\hline 1 & 1-Naphthyl (5a) & $\mathrm{Ph}(\mathbf{6 m})$ & 95 (7am) & $86(S)$ \\
\hline 2 & $2-\mathrm{ClC}_{6} \mathrm{H}_{4}(5 \mathbf{b})$ & $\mathrm{Ph}(\mathbf{6 m})$ & 97 (7bm) & $84(S)$ \\
\hline 3 & $2-\mathrm{BrC}_{6} \mathrm{H}_{4}(5 \mathrm{c})$ & $\mathrm{Ph}(\mathbf{6 m})$ & $95(7 \mathrm{~cm})$ & $84(S)$ \\
\hline 4 & $2-\mathrm{MeOC}_{6} \mathrm{H}_{4}(\mathbf{5 d})$ & $\mathrm{Ph}(\mathbf{6 m})$ & 99 (7dm) & $85(S)$ \\
\hline 5 & $2-\mathrm{MeC}_{6} \mathrm{H}_{4}(\mathbf{5 e})$ & $\mathrm{Ph}(\mathbf{6 m})$ & 98 (7em) & $86(S)$ \\
\hline 6 & $3-\mathrm{MeC}_{6} \mathrm{H}_{4}(\mathbf{5 f})$ & $\mathrm{Ph}(\mathbf{6 m})$ & 96 (7fm) & $80(S)$ \\
\hline 7 & $4-\mathrm{MeC}_{6} \mathrm{H}_{4}(\mathbf{5 g})$ & $\mathrm{Ph}(\mathbf{6 m})$ & 99 (7gm) & $78(S)$ \\
\hline 8 & $4-\mathrm{BrC}_{6} \mathrm{H}_{4}(5 \mathbf{h})$ & $\mathrm{Ph}(\mathbf{6 m})$ & 85 (7hm) & $78(S)$ \\
\hline 9 & 2-Naphthyl (5i) & $\mathrm{Ph}(\mathbf{6 m})$ & 93 (7im) & $82(S)$ \\
\hline 10 & $3,4-\left(\mathrm{OC}_{2} \mathrm{H}_{4} \mathrm{O}\right) \mathrm{C}_{6} \mathrm{H}_{3}(5 \mathbf{j})$ & $\mathrm{Ph}(\mathbf{6 m})$ & 94 (7jm) & $79(S)$ \\
\hline 11 & Ferrocenyl (5k) & $\mathrm{Ph}(\mathbf{6 m})$ & $94(7 \mathbf{k m})$ & $85(S)$ \\
\hline 12 & 1-Naphthyl (5a) & $3,5-\mathrm{Me}_{2} \mathrm{C}_{6} \mathrm{H}_{3}(\mathbf{6 n})$ & 90 (7an) & $87(S)^{d}$ \\
\hline $13^{e}$ & 1-Naphthyl (5a) & $4-\mathrm{MeC}_{6} \mathrm{H}_{4}(\mathbf{6 o})$ & 90 (7ao) & $85(S)$ \\
\hline 14 & 1-Naphthyl (5a) & $3-\mathrm{MeC}_{6} \mathrm{H}_{4}(\mathbf{6 p})$ & 93 (7ap) & $87(S)^{d}$ \\
\hline $15^{e}$ & 1-Naphthyl (5a) & $2-\mathrm{MeC}_{6} \mathrm{H}_{4}(\mathbf{6 q})$ & 87 (7aq) & $91(S)$ \\
\hline $16^{e}$ & 1-Naphthyl (5a) & $2-\mathrm{ClC}_{6} \mathrm{H}_{4}(\mathbf{6 r})$ & 91 (7ar) & $86(R)^{d}$ \\
\hline $17^{e}$ & 1-Naphthyl (5a) & $2-\mathrm{MeO}-5-\mathrm{MeC}_{6} \mathrm{H}_{3}(\mathbf{6 s})$ & 97 (7as) & $85(R)^{d}$ \\
\hline $18^{e}$ & 1-Naphthyl (5a) & 2,6-(MeO) ${ }_{2} \mathrm{C}_{6} \mathrm{H}_{3}(\mathbf{6 t})$ & 80 (7at) & $84(R)^{c}$ \\
\hline $19^{e}$ & 1-Naphthyl (5a) & Mesityl (6u) & 87 (7au) & $94(R)$ \\
\hline $20^{e}$ & $2-\mathrm{ClC}_{6} \mathrm{H}_{4}(5 \mathbf{b})$ & Mesityl (6u) & 70 (7bu) & $94(S)^{d}$ \\
\hline $21^{e}$ & $2-\mathrm{MeC}_{6} \mathrm{H}_{4}(\mathbf{5 e})$ & Mesityl (6u) & 87 (7eu) & $93(R)^{c}$ \\
\hline $22^{e}$ & $2-\mathrm{BrC}_{6} \mathrm{H}_{4}(5 \mathrm{c})$ & $2-\mathrm{MeC}_{6} \mathrm{H}_{4}(\mathbf{6 q})$ & 87 (7cq) & $86(S)^{d}$ \\
\hline $23^{e}$ & Ferrocenyl (5k) & Mesityl (6u) & 85 (7ku) & $84(S)^{d}$ \\
\hline $24^{e}$ & Ferrocenyl (5k) & $2-\mathrm{MeC}_{6} \mathrm{H}_{4}(\mathbf{6 q})$ & 98 (7kq) & $86(S)$ \\
\hline
\end{tabular}

${ }^{a}$ Reaction conditions; $[\mathrm{RhCl}((S, S)-\mathbf{1 f})]_{2}(1 \mathrm{~mol} \%$ of $\mathrm{Rh}), \mathrm{Ar}^{1} \mathrm{CHO}$ $(0.25 \mathrm{mmol}), \mathrm{Ar}^{2} \mathrm{~B}(\mathrm{OH})_{2}(0.50 \mathrm{mmol}), \mathrm{KOH}(0.38 \mathrm{mmol}), t-\mathrm{BuOH}$ $(1.0 \mathrm{~mL})$, at $30{ }^{\circ} \mathrm{C}$ for $3 \mathrm{~h} .{ }^{b}$ Isolated yield. ${ }^{c}$ Determined by HPLC analysis. ${ }^{d}$ The absolute configuration was assigned by analogy with entry $1 .{ }^{e}$ Performed with $[\operatorname{RhCl}((S, S)-1 \mathbf{f})]_{2}$ (3 mol\% of Rh) for $12 \mathrm{~h}$.

analysis with those reported previously. ${ }^{14}$

Table 2 summarizes the results obtained for the reactions of several aldehydes 5 with arylboronic acids $\mathbf{6}$, which were carried out in the presence of $[\operatorname{RhCl}((S, S)-F c-t f b *(1 \mathbf{1 f}))]_{2}$ (1 or $3 \mathrm{~mol} \%$ of $\mathrm{Rh})$. The scope of aldehydes is broad, both 
substituted with electron-withdrawing groups and with electron-donating groups being good substrates to produce diarylmethanols in high yields (entries 1-11). The enantioselectivities in the phenylation of aldehydes having ortho-substituents (entries 1-5) on the benzene ring were higher than those obtained with meta- or para-substituted aromatic aldehydes (entries 6-9). The scope of arylboronic acids is also broad (entries 12-24), where the use of orthosubstituted arylboronic acids displayed higher enantioselectivities of diarylmethanols 7 (entries 13-15 for $\left.\mathrm{MeC}_{6} \mathrm{H}_{4} \mathrm{~B}(\mathrm{OH})_{2}\right)$. Thus, the present catalytic system is effective for the asymmetric synthesis of diarylmethanols having ortho-substituents on both aromatic rings, the enantioselectivity ranging between $84 \%$ and $94 \%$ ee (entries 15-22). The asymmetric double arylation of isophthalaldehyde (8) was also successful using mesitylboronic acid (6u) to give $98 \%$ ee of diol chiral-9 $(75 \%$ yield, chiral $/$ meso $=85 / 15)($ Scheme 4$) .{ }^{17}$

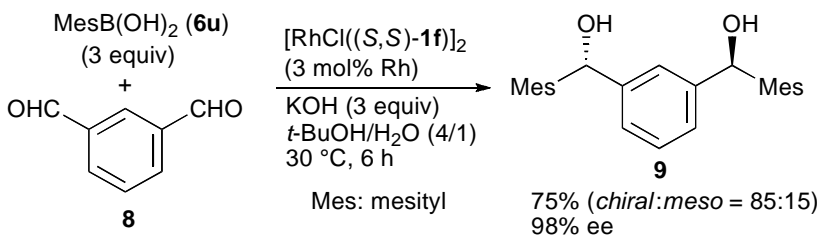

Scheme 4 Asymmetric double arylation of isophthalaldehyde (8).

This work was supported by a Grant-in-Aid for Scientific Research (S) (19105002) from the MEXT, Japan.

\section{Notes and references}

Department of Chemistry, Graduate School of Science, Kyoto University, Sakyo, Kyoto 606-8502, Japan. Fax: +81 75753 3983; Tel: +81 75753 3988; E-mail: tnishi@kuchem.kyoto-u.ac.jp; thayashi@kuchem.kyotou.ac.jp

1 For a review of chiral diene ligands, see: (a) C. Defieber, H. Grützmacher and E. M. Carreira, Angew. Chem., Int. Ed., 2008, 47, 4482. For selected examples of the asymmetric reactions using chiral diene ligands, see: $(b)$ T. Hayashi, K. Ueyama, N. Tokunaga and K. Yoshida, J. Am. Chem. Soc., 2003, 125, 11508. (c) N. Tokunaga, Y. Otomaru, K. Okamoto, K. Ueyama, R. Shintani and T. Hayashi, J. Am. Chem. Soc., 2004, 126, 13584. (d) Y. Otomaru, K. Okamoto, R. Shintani and T. Hayashi, J. Org. Chem., 2005, 70, 2503. (e) K. Okamoto, T. Hayashi and V. H. Rawal, Org. Lett., 2008, 10, 4387. (f) C. Fischer, C. Defieber, T. Suzuki and E. M. Carreira, J. Am. Chem. Soc., 2004, 126, 1628. (g) J.-F. Paquin, C. Defieber, C. R. J. Stephenson and E. M. Carreira, J. Am. Chem. Soc., 2005, 127, 10850. (h) F. Läng, F. Breher, D. Stein and H. Grützmacher, Organometallics, 2005, 24, 2997. (i) S. Helbig, S. Sauer, N. Cramer, S. Laschat, A. Baro and W. Frey, Adv. Synth. Catal., 2007, 349, 2331. (j) Z.-Q. Wang, C.-G. Feng, M.-H. Xu and G.-Q. Lin, J. Am. Chem. Soc., 2007, 129, 5336. (k) T. Noël, K. Vandyck and J. Van der Eycken, Tetrahedron, 2007, 63, 12961. (l) T. Gendrineau, O. Chuzel, H. Eijsberg, J.-P. Genet and S. Darses, Angew. Chem., Int. Ed., 2008, 47, 7669.

2 (a) J. P. N. Brewer and H. Heaney, Tetrahedron Lett., 1965, 6, 4709. (b) J. P. N. Brewer, I. F. Eckhard, H. Heaney and B. A. Marples, J. Chem. Soc. C, 1968, 664. (c) D. D. Callander, P. L. Coe, J. C. Tatlow and A. J. Uff, Tetrahedron, 1969, 25, 25.

3 For a review, see: (a) M. A. Esteruelas and L. A. Oro, Coord. Chem. Rev., 1999, 193-195, 557. For selected examples, see: (b) D. M. Roe and A. G. Massey, J. Organomet. Chem., 1969, 17, 429. (c) D. M.
Roe and A. G. Massey, J. Organomet. Chem., 1971, 28, 273. (d) R. Usón, L. A. Oro, R. Sariego, M. Valderrama and C. Rebullida, J. Organomet. Chem., 1980, 197, 87. (e) R. Usón, L. A. Oro, L. D. Carmona, M. A. Esteruelas, C. Foces-Foces, F. H. Cano, S. GarciaBlanco, J. Organomet. Chem., 1983, 254, 249.

4 (a) T. Nishimura, M. Nagaosa and T. Hayashi, Chem. Lett., 2008, 37, 860. (b) T. Nishimura, Y. Yasuhara, M. Nagaosa and T. Hayashi, Tetrahedron: Asymmetry, 2008, 19, 1778.

5 Compound 3 was prepared by a modified procedure. (a) B. Hankinson and H. Heaney, Tetrahedron Lett., 1970, 16, 1335. (b) P. C. Buxton, N. J. Hales, B. Hankinson, H. Heaney, S. V. Ley and R. P. Sharma, J. Chem. Soc., Perkin Trans. 1, 1974, 2681.

6 A semi-preparative column $(2.0 \mathrm{~cm} \mathrm{I.D.} \times 25 \mathrm{~cm})$ was used for the resolution of $d l-3$. See Electronic Supplementary Information.

7 K. Vandyck, B. Matthys, M. Willen, K. Robeyns, L. Van Meervelt and J. Van der Eycken, Org. Lett., 2006, 8, 363.

8 (a) B. Scheiper, M. Bonnekessel, H. Krause and A. Fürstner, J. Org. Chem., 2004, 69, 3943. (b) G. Berthon-Gelloz and T. Hayashi, J. Org. Chem., 2006, 71, 8957.

9 C. J. O’Brien, E. A. B. Kantchev, C. Valente, N. Hadei, G. A. Chass, A. Lough, A. C. Hopkinson and M. G. Organ, Chem. -Eur. J., 2006, 12, 4743.

10 M. Enders, G. Kohl and H. Pritzkow, J. Organomet. Chem., 2001, 622, 66.

11 Crystal data for $\mathrm{Rh}((S, S)-\mathbf{1 f})\left[\left(\eta^{6}-\mathrm{C}_{6} \mathrm{H}_{5}\right) \mathrm{BPh}_{3}\right]$ (CCDC734763) are reported in Electronic Supplementary Information (CIF).

12 For reviews, see: (a) M. Hatano, T. Miyamoto and K. Ishihara, Curr. Org. Chem., 2007, 11, 127. (b) F. Schmidt, R. T. Stemmler, J. Rudolph and C. Bolm, Chem. Soc. Rev., 2006, 35, 454. (c) L. Pu and H.-B. Yu, Chem. Rev., 2001, 101, 757. (d) K. Soai and S. Niwa, Chem. Rev., 1992, 92, 833. (e) R. Noyori and M. Kitamura, Angew. Chem., Int. Ed. Engl., 1991, 30, 49.

13 For selected examples of asymmetric addition of diphenylzinc to aldehydes, see: (a) P. I. Dosa, J. C. Ruble and G. C. Fu, J. Org. Chem., 1997, 62, 444. (b) C. Bolm and K. Muñiz, Chem. Commun., 1999, 1295. (c) W.-S. Huang and L. Pu, J. Org. Chem., 1999, 64, 4222. For selected examples of asymmetric addition of diarylzinc generated from arylboron reagents, see (d) C. Bolm and J. Rudolph, $J$. Am. Chem. Soc., 2002, 124, 14850. (e) S. Dahmen and M. Lormann, Org. Lett., 2005, 7, 4597. (f) J.-X. Ji, J. Wu, T. T.-L. Au-Yeung, C.W. Yip, R. K. Haynes and A. S. C. Chan, J. Org. Chem., 2005, 70, 1093. (g) X. Y. Liu, X. Y. Wu, Z. Chai, Y. Y. Wu, G. Zhao and S. Z. Zhu, J. Org. Chem., 2005, 70, 7432. (h) A. L. Braga, D. S. Lüdtke, F. Vargas and M. W. Paixão, Chem. Commun., 2005, 2512. (i) M.-J. Jin, S. M. Sarkar, D.-H. Lee and H. Qiu, Org. Lett., 2008, 10, 1235.

14 Enantioselectivity up to $87 \%$ (ref. 14e) has been reported. (a) M. Sakai, M. Ueda and N. Miyaura, Angew. Chem., Int. Ed., 1998, 37, 3279. (b) T. Focken, J. Rudolph and C. Bolm, Synthesis, 2005, 429. (c) W. Zhang, Y. Qin, S. Zhang and M. Luo, ARKIVOC, 2005, 14, 39. (d) R. B. C. Jagt, P. Y. Toullec, J. G. de Vries, B. L. Feringa and A. J. Minnaard, Org. Biomol. Chem., 2006, 4, 773. (e) H.-F. Duan, J.-H. Xie, W.-J. Shi, Q. Zhang and Q.-L. Zhou, Org. Lett., 2006, 8, 1479. (f) T. Arao, K. Sato, K. Kondo and T. Aoyama, Chem. Pharm. Bull., 2006, 54, 1576. (g) K. Suzuki, K. Kondo and T. Aoyama, Synthesis, 2006, 1360. (h) K. Suzuki, S. Ishii, K. Kondo and T. Aoyama, Synlett, 2006, 648. (i) T. Arao, K. Suzuki, K. Kondo and T. Aoyama, Synthesis, 2006, 3809.

15 (a) T. Arao, K. Kondo and T. Aoyama, Tetrahedron Lett., 2007, 48, 4115. (b) K. Yamamoto, K. Tsurumi, F. Sakurai, K. Kondo and T. Aoyama, Synthesis, 2008, 3585.

16 Highly enantioselective ruthenium-catalyzed arylation has been reported very recently. K. Kurihara, Y. Yamamoto and N. Miyaura, Angew. Chem., Int. Ed., 2009, 351, 4414.

17 K. Soai, Y. Inoue, T. Takahashi and T. Shibata, Tetrahedron, 1996, 52, 13355. 